\title{
Women, competition and beliefs
}

Noémi Berlin

Women are under-represented in highly competitive top positions in corporations, in governments, and in academia such that they make up between 15\% and 30\% of these positions in most of the developed countries (see as an example figure 1 that shows women's share of employment in senior and middle managements). This share has increased since 1996, but very slowly. Moreover, the gender wage gap, despite some progress since 2006 still exists, such that in developed countries, for the same job, a man is likely to earn about $20 \%$ more than a woman.

For many years now, researchers have tried to come up with explanations for these gaps. Through different theories and observations, men and women are found to exhibit differences such as in the value given to the time spent with their children, a different perception of holding high-level positions (Gino et al., 2015), bargaining ability (Bowles et al., 2007; Mazei et al., 2015), or discrimination. Indeed, researchers have raised the question of role incongruity (Koenig et al., 2011), an inconsistency arising because women's expected characteristics (kindness, compassion, warmth) differ from the expected characteristics of a manager or a negotiator (assertive, competitive, demanding) which are usually considered as more masculine. Hence, women are not considered for these types of positions or are less likely to negotiate their wage, and end up with a lower position and salary. Those stereotypes impact the decisions of employers and make it harder for women to obtain leadership jobs.

As opposed to employers who decide to hire according to potential stereotypes, the way women behave or make their own education and career decisions can also explain those gender differences. Schuh et al. (2014) raise the issue 
of power motivation that they define as "an interpersonal difference in the desire to influence others (McClelland, 1985; Miner, 1975)". According to the authors, men have higher power motivation which would affect their aspiration level and consequently their leadership occupancy achievement, compared to women.

Recent work in behavioural economics has addressed other explanations for the lack of women in promoted posts. This paper focuses on one of them, which is that women avoid competition. If that is the case, women would choose to enter less-competitive tracks, hence missing the chance of succeeding in competitions that lead to higher positions on the labour market where they are then under-represented.

With a laboratory experiment methodology, and by using a simple task (adding five two-digit numbers) Niederle \& Vesterlund (2007) show that when women and men are asked to enter a tournament or not, in which pay-offs would be earned conditional on winning the tournament, a significant gender gap appears. Men do enter the competition, while women self-select themselves out of entering it. It becomes even more surprising that this gender gap persists even when comparing the decisions of men and women of the same performance level. This non-optimal decision hence implies a loss in global welfare. The gender gap in competitive entry is robust and has been found in various later papers (for example: Datta Gupta et al., 2013; Booth \& Nolen, 2012; Kamas \& Preston, 2009; Vandegrift \& Yavas, 2009; Ertac, 2011; Dohmen \& Falk, 2011) which consider other types of tasks, look at different age groups and identify other circumstances such as the gender of the opponent. One interesting result from Gneezy et al. (2009)

Female share of employment in senior and middle management (\%)

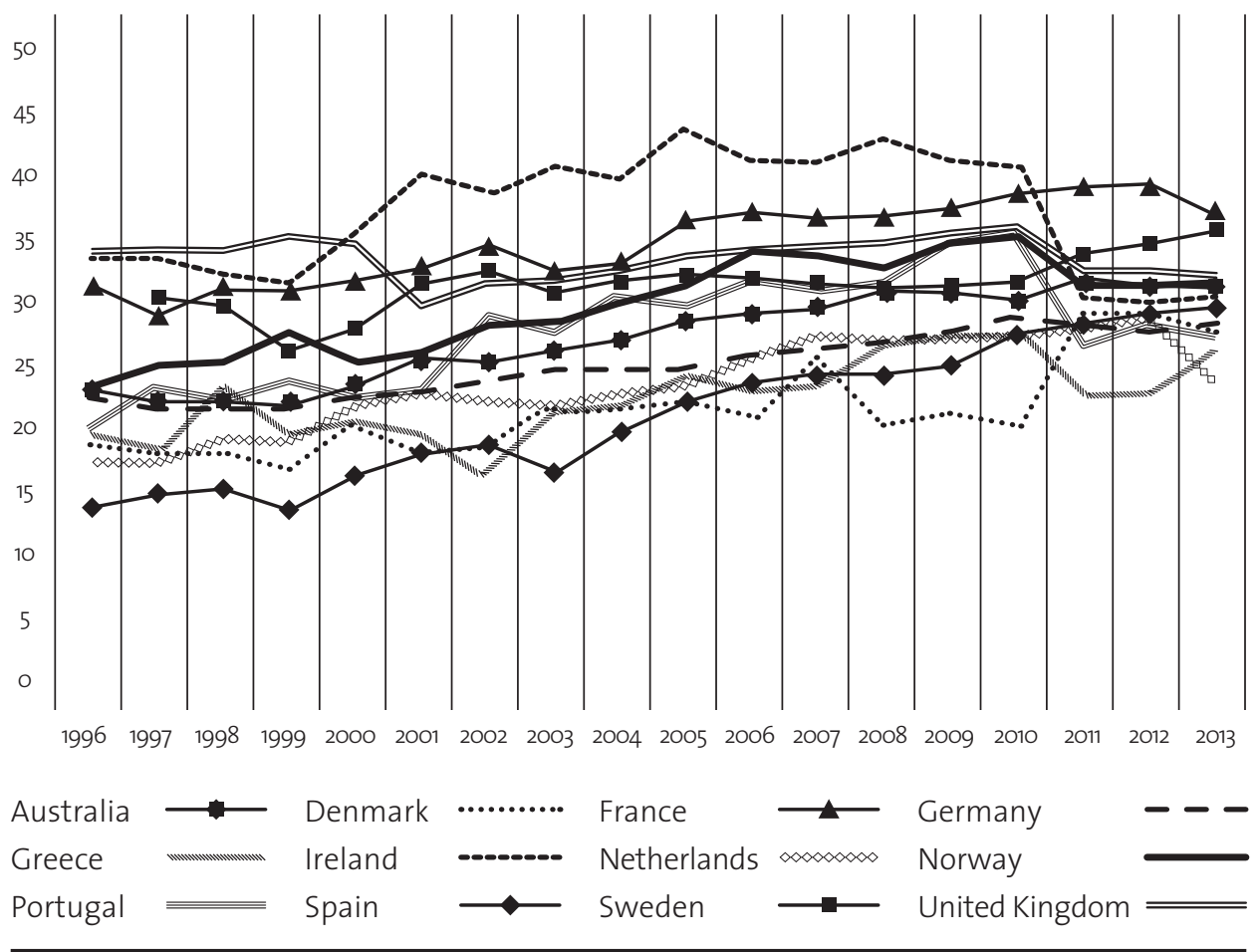

Table 1. Source: International Organisation of Labour, available statistics. 
is that the gender gap in competition is reversed in a matriarchal society compared to a patriarchal one, showing that cultural differences and the way women are considered in society impact the competitive behaviours of both men and women.

In societies where gender differences are less in favour of women, the women seem to not enjoy competition even when they have the ability to benefit more from this "scheme". Different reasons for their competition avoidance have been studied in the literature such as risk attitudes or beliefs. Here we are interested in the latter.

Let's place ourselves into a general economics framework where one considers the decision to engage oneself in any kind of competition. That means one faces opponents and one has to perform better than them in order to win the competition. When analysing the decisions to compete or not, economists will consider self-confidence as the belief, which is a subjective probability, of succeeding in the task involved. Those beliefs will play an important role in the process of decision-making. The person making the decision will take into account all the available information in her environment: the opponents, the difficulty they think of the task, the setting (number of opponents, of rounds, etc), and how likely they think it is that they can win (self-confidence). If one has very low confidence in one's success, then one will avoid the tournament thinking that one will lose, even though it is objectively not true. We call this under-confidence. Overconfidence can of course also arise, implying an increase in the motivation in performing the task, with sometimes a higher risk of failing. And in a sense, failure might also be perceived differently by men and women.

When looking at the self-confidence of men and of women, a robust result is found such that men are usually more confident than women. Many psychologists found these results before the economists (Lichtenstein et al., 1982; Beyer, 1990; Beyer \& Bowden, 1997; Pulford \& Colman, 1997). Previous research shows that people are generally overconfident in diverse areas such as cardriving, investment decisions, entrepreneurial behaviour, running, stock market forecasts (for example: Beckmann \& Menkhoff, 2008; Bohnet, 2016; Croson \& Gneezy, 2009;

Deaves, 2010; Koellinger et al., 2007; Svenson, 1981). Even when both men and women are over-confident, men are even more overconfident than women. So it might be the case that this lack of self-confidence does not push women enough to choose competition.

One solution to increase confidence in this type of situation is to create competition in teams. A study by Healy \& Pate (2011) shows that competing in two-person teams reduces the gender competition gap by two-thirds. Moreover, women prefer to compete in teams whatever the sex of their partner whereas men prefer to compete as individuals. Another study, Dargnies (2012), finds that high-ability men are reluctant to enter the competition in a team because they fear being the victim of a teammate's free-riding behaviour.

If we consider a real-life example such as choosing an educational track, it might be very well the case that in very selective tracks we observe fewer women not because they are discriminated against, nor because they have no taste for the track, but because they self-select themselves from not going into this track. They may choose one that they would think easier or in which they are more confident (Ayalon, 2003; Bettinger \& Long, 2005). But everything is related, and the confidence they build may also be related to a stereotype threat that women (and men) integrate at very young ages (Spencer et al., 1999). For instance, if people believe that mathematics or sciences are for men and humanities are for women, then it is very likely you will find more men in the science tracks and women in the humanities tracks. If people believe that competition is for men rather than for women, men will be more likely to be found in competitive situations. The hard task is to be able to disentangle the actual taste for the discipline or the competition, from stereotype effects or competition avoidance based on wrong beliefs. A solution to this misallocation could be to provide people with better information. For instance, relative feedback on their performance should decrease the uncertainty, soften existing stereotypes, 
and might facilitate decision-making in a competitive environment and reduce the gender gap (see Bohnet, 2016). However, the psychology literature suggests that women incorporate negative information more than men, with the opposite occurring for positive information (for example, Roberts \& Nolen-Hoeksema, 1989). In economics, Berlin \& Dargnies (2012) tend to confirm this result such that women seem to respond more strongly to the information they receive and especially to negative information. Hence, non-optimal selfselection because of negative information is found more for women than men, which means that providing information also has some drawbacks. It could very well be the case that women and men seek and value information differently. It seems that women exhibit a demand for information when they already know about the level of their ability whereas men will ask for information if they are uncertain of their abilities.

Why do we observe this discrepancy in beliefs and in demand for information? Are there any other ways to encourage women to choose to compete in the workplace when it is actually more beneficial than not to compete? It is a very complex issue. On the one hand, we do observe that men and women would react in different ways according to the same information they receive which has an impact on decisions they might make. Because we observe this difference, it does not mean, on the other hand, that women need to be treated differently. Because men and women do not differ in their ability level, one has to improve the information process made by women so they can make more optimal decisions for their career and manage to reach the same status as men, if that is what they wish for.

Maybe it is the case that women take too much account of what others think of them, which is not the case for men. To our knowledge, even though results on the analysis of beliefs tend to point in that direction, there are no clear results. Moreover, evolving in an environment mainly dominated by men is not easy. Women can be judged for not meeting role stereotypes, and both men and women can expect a specific behaviour from women that they would not expect from men (likeability, ability in some fields) which makes the stereotype threat a real issue (see role incongruity discussed earlier). You may even hear that women either have to become a "shark" and more aggressive, scaring their female and male counterparts to achieve higher positions, or that they are not affirmative enough and can be eaten by the "sharks", whatever their gender.

Particular attention should be paid to situations where incorrect self-selection can arise. Every time an individual selfselects herself from continuing to the most difficult track and chooses an easier option, authorities and policies should make sure this choice is not based on biased beliefs (underestimation). Not all women and men have the ability or aspiration to reach top positions, but because we know that men are no better than women, tools for women should be developed so they can overcome their fear of competition. Equality in that case is not a question of saying that men or women are the same but that, when the same objective measures between a man and a woman are observed (such as abilities), the same behaviour should also be observed. However, as Gino et al. say about existing data:

We cannot make value judgments about whether men's and women's differing views of professional advancement are good or bad, rational or irrational, at any level of analysis (e.g., for individuals, for organizations, or for societies). It is possible that men and women are correctly predicting the unique experiences that they are poised to encounter upon professional advancement and are making sound decisions accordingly. (Gino et al., 2015)

What maybe matters is that women manage to do what men do, if that is what they want.

The understanding of these different mechanisms will hopefully provide insights for policymaking to drive men's and women's behaviours towards situations in which each are satisfied, and leading eventually, in a few years, to a significant decrease in the gender gap. 